This item was submitted to Loughborough's Institutional Repository (https://dspace.lboro.ac.uk/) by the author and is made available under the following Creative Commons Licence conditions.

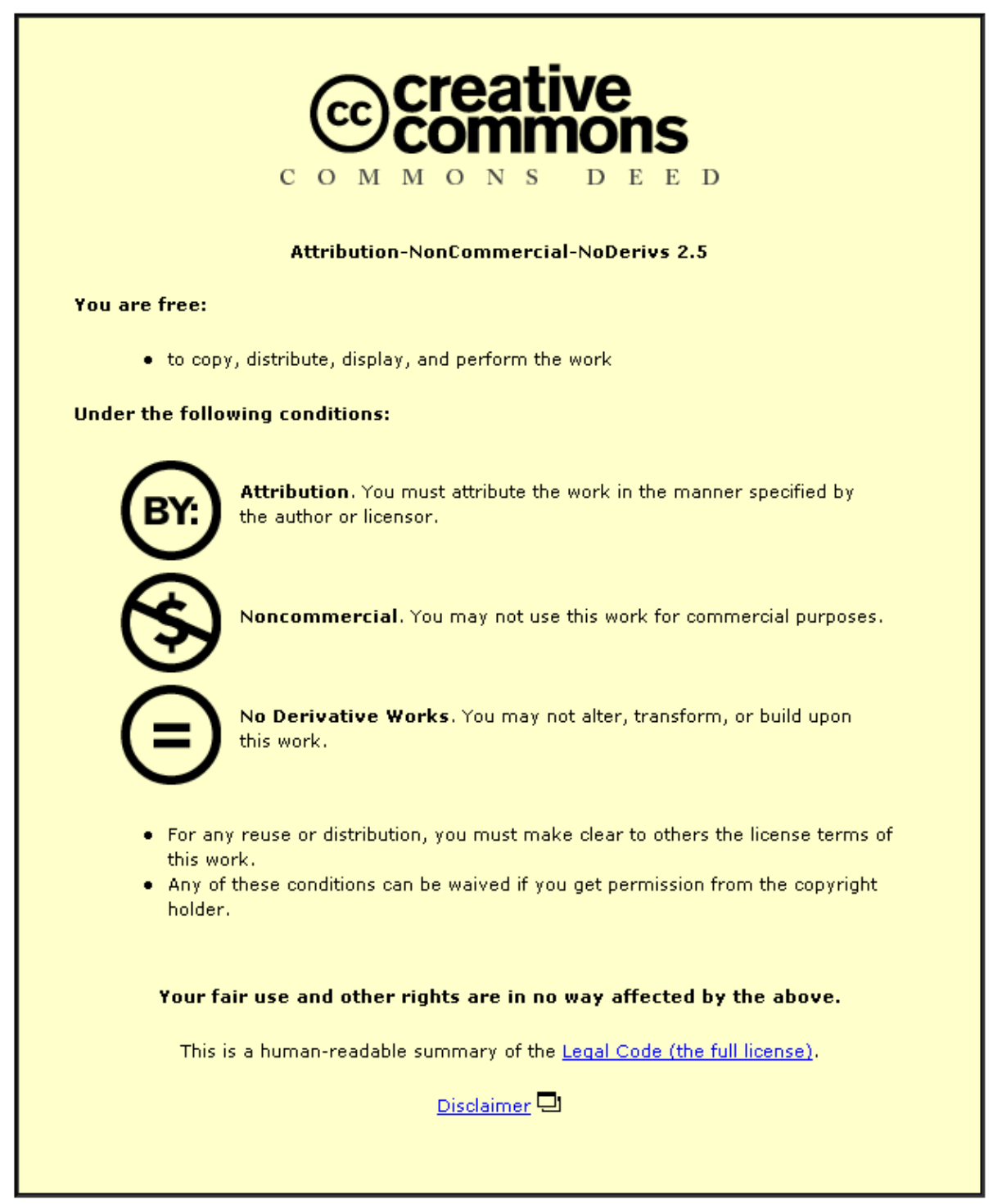

For the full text of this licence, please go to: http://creativecommons.org/licenses/by-nc-nd/2.5/ 


\title{
The influence of simulation model complexity on the estimation of internal loading in gymnastics landings.
}

\author{
Chris Mills ${ }^{1}$, Matthew T.G. Pain ${ }^{2}$ and Maurice R. Yeadon ${ }^{2}$ \\ ${ }^{1}$ School of Sport and Health Sciences, University of Exeter, St. Luke's Campus, EX1 2LU. \\ ${ }^{2}$ School of Sport and Exercise Sciences, Loughborough University, Ashby Road, Loughborough, LE11 $3 T U$.
}

\begin{abstract}
Evaluating landing technique using a computer simulation model of a gymnast and landing mat could be a useful tool when attempting to assess injury risk. The aims of this study are: to investigate whether a subject-specific torque-driven or a subject-specific muscle-driven model of a gymnast is better at matching experimental ground reaction forces and kinematics during gymnastics landings, to calculate their respective simulation run times and to determine what level of model complexity is required to assess injury risk. A subject-specific planar seven link wobbling mass model of a gymnast and a multi-layer model of a landing mat were developed for this study. Subject-specific strength parameters were determined that defined the maximum voluntary torque / angle / angular velocity relationship about each joint. This relationship was also used to produce subject-specific 'lumped' muscle models for each joint. Kinetic and kinematic data were obtained during landings from backward and forward rotating gymnastics vaults. Both torque-driven and muscle-driven models were capable of producing simulated landings that matched the actual performances (with overall percentage differences between $10.1 \%$ and $18.2 \%$ ). The torque-driven model underestimated the internal loading on joints and bones, resulting in joint reaction forces that were less than $50 \%$ of those calculated using the muscle-driven model. Simulation time increased from approximately three minutes (torquedriven) to more than ten minutes (muscle-driven) as model complexity increased. The selection of a simulation model for assessing injury risk must consider the need for determining realistic internal forces as the priority despite increases in simulation run time.
\end{abstract}

\section{Introduction}

When landing from a dismount in Artistic Gymnastics the aim is to reduce the velocity of the mass centre to zero whilst over the base of support and within a single placement of the feet. Any steps or unsteadiness during landing can result in a score deduction between 0.1 and 0.3 (F.I.G., 2001). The successful landing from a vault (or other apparatus) poses a problem for a gymnast who must trade off technical difficulty with the probability of a successful landing and with the risk of injury. While minimising injury is a concern it is not always of paramount importance in competitive environments, such as at the Atlanta 1996 Olympics Games where an already injured gymnast completed a vault, further exacerbating her injury. The gymnast and coach aim to maximise performance and develop training regimes and technical strategies to achieve this. Similarly most of the computer simulation research in gymnastics, jumping and landing has been aimed at improving performance (Hiley and Yeadon, 2003; King and Yeadon, 2004) and has not considered the potential injury risks. Using a gymnast to investigate different landing techniques experimentally could lead to injury. On the other hand a forward dynamics computer simulation model of a gymnast and landing mat could be used to look at the performance enhancement of various landing techniques and gymnastic skills whilst safely assessing the associated injury risk.

It has been reported that between $57 \%$ and $82 \%$ of injuries in gymnastics are acute, ranging from strains and sprains to fractures and dislocations, and that the lower extremity was the most injured, comprising 54\% to 70\% of all injuries (Andrish, 1985; Harringe et al., 2006; Jensen, 1998; McAuley et al., 1987; Meeusen and Borms, 1992; Snook, 1979). 31\% of acute injuries were fractures to the lower extremity (Pettrone \& Ricciardelli, 1987); the foot was mentioned separately, suggesting that the fractures were to the femur and tibia/fibula. 
Impact forces acting on the human body during landing must be dissipated primarily by the musculoskeletal system and excessive loading may result in injury (McNitt-Gray et al., 2000). Previous experimental research has focused on landing from various drop heights (DeVita and Skelly, 1992; Dufek and Bates, 1990; McNitt-Gray et al., 1993 and 1994; Ozguven and Berme, 1988). The results have shown that the amount of joint flexion, rate of joint flexion, landing phase duration, and ground impact forces generally increased with greater drop height. Factors affecting the dissipation of forces during landing have been identified as the landing strategy (Dufek and Bates, 1990; McNitt-Gray et al., 1993) and the landing mat (McNitt-Gray et al., 1994). Landing mats undergo large amounts of area deformation and are now essential for landings from gymnastics apparatus dismounts and vaults. As large numbers of the injuries in gymnastics occur due to excessive loading of the lower limbs during landings is relevant to determine what effect changes in landing conditions have on internal loading.

Within biomechanics both torque-driven models (Alexander, 1990, Chowdhary and Challis, 1999; King et al., 2006) and muscle-driven models (Cole et al., 1996; Denoth, 1985; Spagale et al., 1999) have been used to generate active joint motion. An advantage of torquedriven models is that they can be implemented with subject-specific torque/angle/angular velocity profiles (King et al., 2006). Since they represent the net effect of all the muscles contributing to movement about a joint they cannot be used to investigate the role of individual muscles. Torque-driven models also fail to account for all the internal forces at the joints since the action of a linear muscle effects a moment and produces a reaction force in the joint, whereas a torque generator does not.

In a forward dynamics simulation the joint reaction force is calculated as the sum of force vectors at the joint that arise from the mechanical components (for example: rigid bodies, springs and linear actuators) that are present in the model. Simulation time is crucial when attempting to optimise a landing technique since a large number of iterations must be run. A simpler model may run faster than a more complex model, but it may lack some important aspects that are critical to the problems being investigated. As a consequence it is essential to evaluate any such model with these considerations in mind.

The aims of this study are: to develop a model to investigate whether a subject-specific torque-driven or a subject-specific muscle-driven model of a gymnast, in conjunction with a model of a landing mat, is better at matching measured ground reaction forces (GRFs) and kinematics during gymnastics landings, to calculate their respective simulation run times, to determine what level of model complexity is required to assess injury risk through the calculation of joint reaction forces (JRFs) and bending moments in the femur and tibia within the models. Injury risk will be defined as increased internal loading in terms of joint reaction forces and bone bending moments. The level at which injury will occur will be not defined as there are no known in vivo values for subject-specific injuries. Hence, only the generic risk of injury from increased loading can be assessed rather than the probability of injury.

\section{Methods}

Data Collection

Three-dimensional motion data, force plate data and electromyography (EMG) recordings were obtained during the landings of one forward rotating (FR) and one backward rotating (BR) vault performed by an elite gymnast (height $1.77 \mathrm{~m}$, weight $75 \mathrm{~kg}$ ) in a simulated competition environment. The gymnast gave informed consent for all procedures, which were carried out in accordance with the protocol approved by the Ethical Advisory Committee of Loughborough University.

Motion data were recorded at $250 \mathrm{~Hz}$ using a 12 camera Vicon 624 motion analysis system in a calibrated volume $3.5 \mathrm{~m}$ long by $2 \mathrm{~m}$ wide by $3.5 \mathrm{~m}$ high with a reconstruction 
residual of $1.2 \mathrm{~mm}$. Retro-reflective markers ( $25 \mathrm{~mm}$ diameter) were placed at the lateral aspect of the shoulder, elbow, wrist, hip, knee, ankle, and metatarsal-phalangeal joints and the head and toes on both sides of the body. An AMTI force plate measuring $1200 \mathrm{~mm}$ by $600 \mathrm{~mm}$ was located beneath a customised landing mat which had a section the size of the force plate separate from the rest of the mat to minimise cross-bridging. Force data were collected at a sampling frequency of $1000 \mathrm{~Hz}$ with a 10\% pre-trigger and a sampling duration of five seconds. EMG data were collected at $1000 \mathrm{~Hz}$, with a gain of 3000, from the gastrocnemius, tibialis anterior, biceps femoris, vastus lateralis, rectus femoris and gluteus maximus on the on the right side of the gymnast using a portable Biovision EMG system. The EMG system, the force plate and the Vicon motion analysis system were all synchronised using a radio signal.

\section{Data Processing}

Personalised segmental inertia parameters for the gymnast were calculated (Table A1) using the inertia model of Yeadon (1990); these were then divided into the rigid and wobbling mass inertial parameters (Table A2) based upon Pain and Challis (2006). Subject-specific strength parameters for the gymnast were calculated (Table A3) using a nine-parameter mathematical function based on the seven parameter maximum voluntary torque/angular velocity function of Yeadon et al. (2006). The two extra parameters defined the torque/angle relationship and determined the torque/angle/angular velocity relationship using methods similar to King et al. (2006). Obtaining the muscle model parameters involved the subject performing a series of maximal effort isometric trials and eccentric - concentric cycles on a dynamometer.

The Vicon marker positional data were smoothed using a generalised cross-validated spline (Woltring, 1986) and the splined positional data were used to calculate the gymnast's joint angles and trunk orientation angle during the final $150 \mathrm{~ms}$ prior to landing and throughout the landing phase of the skill. The splined data were also used to calculate the mass centre velocity, the joint angular velocities and the trunk angular velocities throughout the landings. The raw EMG signals were full wave rectified and low pass filtered at $6 \mathrm{~Hz}$ using a second order Butterworth filter. EMG data were recorded during the run up, vault and landing and the peak value for the filtered signal for each muscle was determined and was used as the maximum activation level (1.0). The EMG data $150 \mathrm{~ms}$ prior to contact were analysed to help determine viable activation levels at touchdown. As it takes time to change activation levels, achievable values depend upon the past history. If the instant of touchdown was taken independently of previous motion and activation, activation levels could be set that are plausible for that instant in time, but may have required impossible combinations of kinematic and activation profiles prior to touchdown.

\section{Simulation Models}

Three forward dynamics planar link models representing the gymnast were constructed in visualNastran 4D (VN4D) to simulate the first $100 \mathrm{~ms}$ of landing. The gymnast models were comprised of a head + trunk, upper arm, lower arm + hand, thigh, shank and a two-segment foot; pin joints connected adjacent links at their ends and along the longitudinal axis of the segment. Wobbling masses were connected (Table A4) to the rigid links of the trunk, thigh and shank to represent soft tissue movement (Figure 1). The rigid links of the shank and thigh were made of two equal parts connected by rigid joints so that moments could be calculated in the middle of these links. Using the two part bone link to calculate bending moments is a simple method to determine the magnitude of the loading on the skeletal structure and can be related to the fracture failure of bones from in-vitro tests. However, live bone is normally stronger than in-vitro bone specimens and also has the advantage that muscle and other soft tissue surround it. These simple bending moment calculations ignore 
such things as pre-stressing the bones with muscular tension, ligamentous and tendinous support, and given the model is two dimensional, it does not account for three-dimensional loading. Thus accurate values for loading on the bones cannot be achieved but the magnitude of the underestimation of internal loading using torque driven models compared to linear models can be determined. The only important difference in terms of the features of the models was the way in which joint torques were produced. These were (a) torque driven (Model One), (b) torque driven with SEC (Model Two) and (c) linear actuator with SEC (Model Three). In Models One and Two the joint reaction force was equivalent to net joint reaction force and in Model Three it was similar to a bone on bone force (although forces generated by passive tissues such as ligaments will be ignored). Joint reaction forces and bending moments were calculated throughout each simulation.

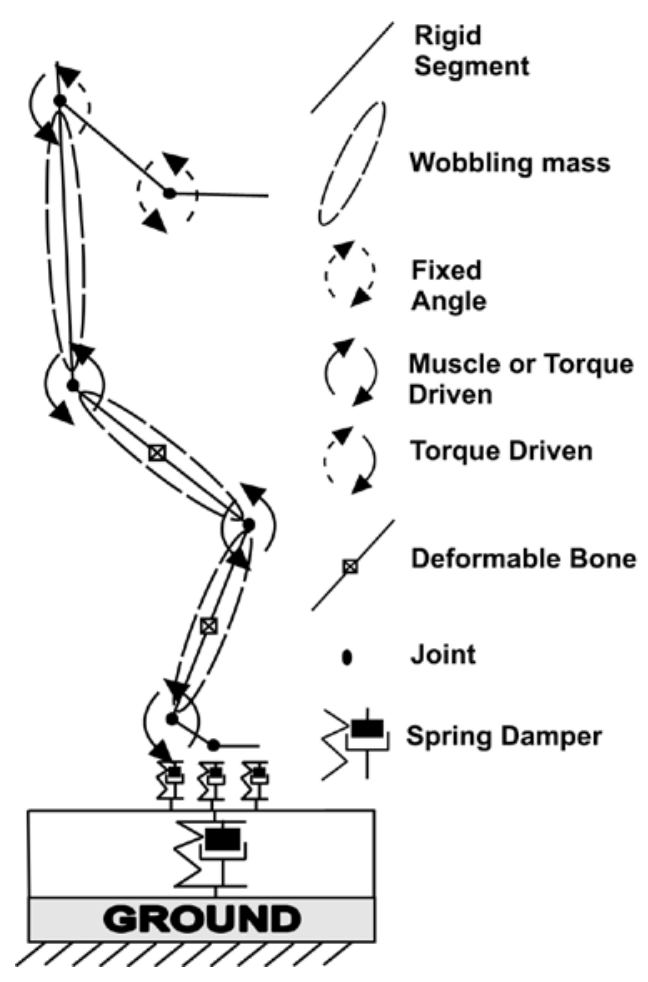

Figure 1. The seven segment planar simulation model with damped springs representing the elastic properties of the landing mat and the gymnast.

The muscle models were implemented in MatLab and Simulink was used to integrate the VN4D link model, the muscle models and the optimization routines. As the various muscle models connected to the VN4D link model in different ways, three separate models were constructed. All computations were carried out on a Pentium $42.66 \mathrm{GHz}$ processor with $512 \mathrm{Mb}$ of RAM.

In Models One and Two torque generators at the ankle, knee, hip and shoulder were used to generate joint motion. The torque produced at each joint after each time step was a product of the nine-parameter voluntary maximum torque function (King et al., 2006) and the muscle activation level (Table A3). In Model One the contractile component (CC) was represented by the torque generator but there was no series elastic component (SEC). Model One was the simplest method for driving the model with muscle-like torque / angle / angular velocity characteristics specific to the subject. This allowed the model to run faster during optimisations whilst still permitting the model to be evaluated against kinetic and kinematic parameters that could be measured externally. In Model Two a rotational elastic element 
(Table A5) was included in series with the torque generator allowing the contractile component to operate in more favourable angle-angular velocity regimes and produce higher torques than would be expected from the joint angle-angular velocity values. In Model Three the torque generator at each joint was replaced with a 'lumped' linear muscle model. Model Three was the simplest method of moving from an angularly controlled system to a linearly controlled system whilst maintaining the subject-specific nature of the strength parameters and including a series elastic component.

The 'lumped' muscle model represented all the muscles responsible for a particular joint's flexion or extension grouped together and used a single linear actuator for each direction. The linear actuator was attached at one end to one body segment and at the other to a point on the circumference of a circle centred at the joint centre while the SEC was attached to another point on the circle and then to the second body segment (Figure 2). Apart from the knee flexors the muscles were attached at the origin and insertion of the major single joint muscles: soleus, tibialis anterior, vasti, gluteus maximus and psoas. To avoid the knee flexor muscle model crossing two joints, as the hamstrings do in reality, the knee flexor's origin was placed at the back of the leg, at the same height as the extensor's origin, and the insertion was the average of the hamstrings on the tibia. This allowed the linear actuator to act with a moment arm scaled to the subject from the midpoint of the ranges in the appendix for the selected muscles (Table A5, Duda et al., 1996; Jacobs et al., 1996). The torque at a joint was calculated from the nine-parameter function in Model One and was then divided by the moment arm to give the force in the lumped linear actuator.

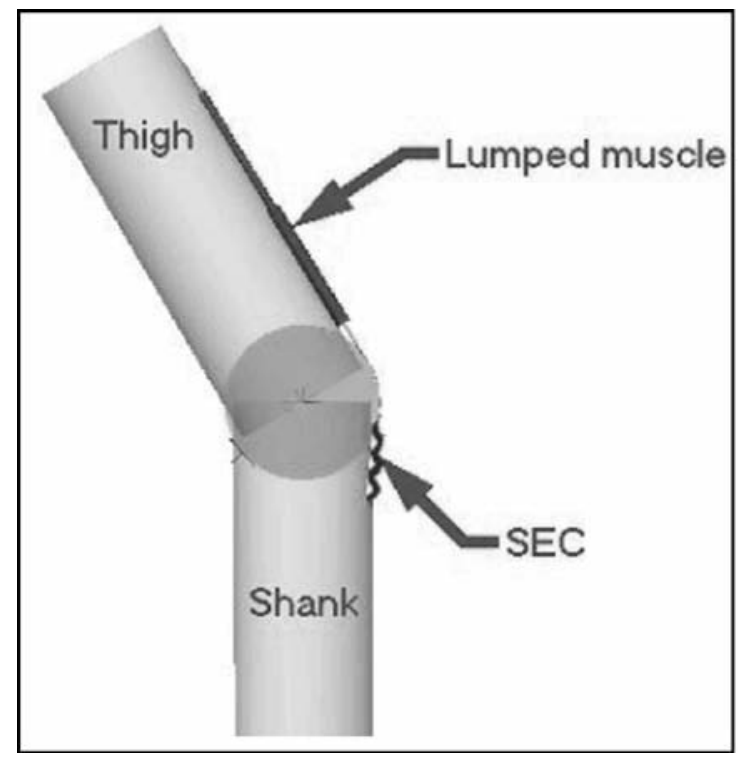

Figure 2. Mechanical structure of the knee extensor lumped muscle model (linear actuator) and the series elastic component (SEC).

The landing mat model was implemented in VN4D and had the capability of being used independently of the gymnast model. This mat model was based upon a multi-layer springdamper design and was evaluated using impact tests that were independent of the gymnastics landing trials (Mills et al., 2006). The behaviour of the landing mat to impulsive loading was measured independently using a set of material tests (Pain et al., 2005) in order to determine its mechanical properties (Table A6). 


\section{Parameter Determination and Model Evaluation}

During a matching simulation of a landing the only parameters allowed to vary were the magnitude and timing of the muscle model activations. The time history of the activation of each muscle was parameterised by initial and final activation levels, ranging from 0.1 to 1.0 for the extensors and from 0.75 to 0.05 for the flexors, and the times of initial and final activations (Figure 3). The smooth change in activation defined by these four parameters was described using a quintic function with zero first and second endpoint derivatives (Hiley and Yeadon, 2003).

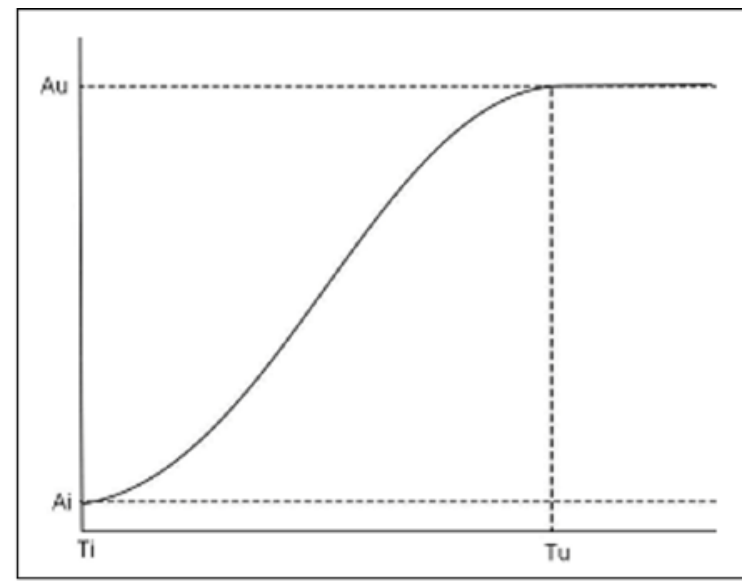

Figure 3. Four parameter profile for muscle activation. Ai is the initial activation level, Ti is the start of ramp up, $\mathrm{Au}$ is the final activation level and Tu is the time final activation level is reached.

The Simplex optimisation algorithm was used to determine the activation parameters required to match a simulation to the experimental landing data. Initial conditions, comprising limb and whole body positions and velocities, for the model and the gymnast were matched at the instant of touchdown (Table A7). Due to potential movement artifact and soft tissue motion relative to the EMG electrodes during violent landings, the EMG signal prior to landing was used as the starting point for the activation profile optimization (Table A8) and the final activation level in the first optimization run was the maximum or minimum allowed. The activation levels in Table A8 are from 0 to 1 ( 1 indicating that the leg is maximally activated). The activation is multiplied by two in the simulation to give the activation level of both legs.

Weighted root mean square (RMS) differences between measured experimental values for successful landings and simulated values of GRF's, joint angle time histories of the ankle, knee, hip and shoulder, and trunk orientation time history were used to give an matching score (equation 1), which was minimised during optimisation.

$$
S=\left[\% V G R F+\% H G R F+\frac{1}{4} \sum \% \text { Joint Angles }+{ }^{\circ} \text { Trunk Angle }\right]
$$

where the vertical (VGRF) and the horizontal (HGRF) ground reaction forces are expressed as percentages of the peak forces and the joint angles are expressed as percentages of the joint ranges. This score was chosen as it gave approximately equal weight to the matching of motion and forces. 


\section{Results}

Reasonably close agreement was found between the recorded performances and the matching simulations for all three models (Table 1). All three models were able to match the performances of the forward rotating vault better than the backward rotating vault. Model Three produced the best match between the measured and simulated force time histories (Figure 4). Model Two struggled to match the VGRF time history during the forward rotating vault resulting in a simulated peak force $36.9 \%$ lower than the measured peak force during impact (Figure 4). Model Three was able to match the peak VGRF during a forward rotating vault to within $6.7 \%$ of the measured peak force. All three models failed to match the unusual HGRF time history produced during the backward rotating vault (Figure 4). Model One took 165 seconds to run a single simulation compared to 210 seconds for Model Two and 630 seconds for Model Three and hence required the longest optimisation time. An increase in model complexity results in an increase in simulation time, this in turn increases optimisation times to approximately one week in the case of Model Three as many thousands of simulations had to be run during a single optimisation.

Table 1. Error in matching score breakdown for three gymnast-mat models. BR is backwards rotating and FR is forwards rotating.

\begin{tabular}{|c|c|c|c|c|c|c|c|}
\hline $\begin{array}{c}\text { Model } \\
\text { Number }\end{array}$ & Skill & $\begin{array}{c}\text { Score } \\
\%\end{array}$ & $\begin{array}{c}\text { VGRF } \\
\%\end{array}$ & $\begin{array}{c}\text { HGRF } \\
\%\end{array}$ & $\begin{array}{c}\text { Trunk } \\
\circ\end{array}$ & $\begin{array}{c}\text { Joint } \\
\text { Angles } \\
\%\end{array}$ & $\begin{array}{c}\text { Joint } \\
\text { Angles } \\
\circ\end{array}$ \\
\hline \multirow{2}{*}{1} & BR & 18.2 & 14.9 & 36.3 & 0.8 & 20.9 & 10.7 \\
\cline { 2 - 8 } & FR & $\mathbf{1 1 . 9}$ & $\mathbf{2 0 . 7}$ & $\mathbf{1 5 . 1}$ & $\mathbf{3 . 8}$ & $\mathbf{8 . 1}$ & $\mathbf{4 . 3}$ \\
\hline \multirow{2}{*}{2} & BR & 17.6 & 14.9 & 35.8 & 0.8 & 19.0 & 9.9 \\
\cline { 2 - 8 } & FR & $\mathbf{1 3 . 9}$ & $\mathbf{2 5 . 7}$ & $\mathbf{1 2 . 7}$ & $\mathbf{5 . 1}$ & $\mathbf{1 2 . 2}$ & $\mathbf{6 . 4}$ \\
\hline \multirow{2}{*}{3} & BR & 16.2 & 12.1 & 36.1 & 0.8 & 15.7 & 6.9 \\
\cline { 2 - 8 } & FR & $\mathbf{1 0 . 1}$ & $\mathbf{1 6 . 8}$ & $\mathbf{1 2 . 3}$ & $\mathbf{4 . 6}$ & $\mathbf{6 . 6}$ & $\mathbf{3 . 6}$ \\
\hline
\end{tabular}
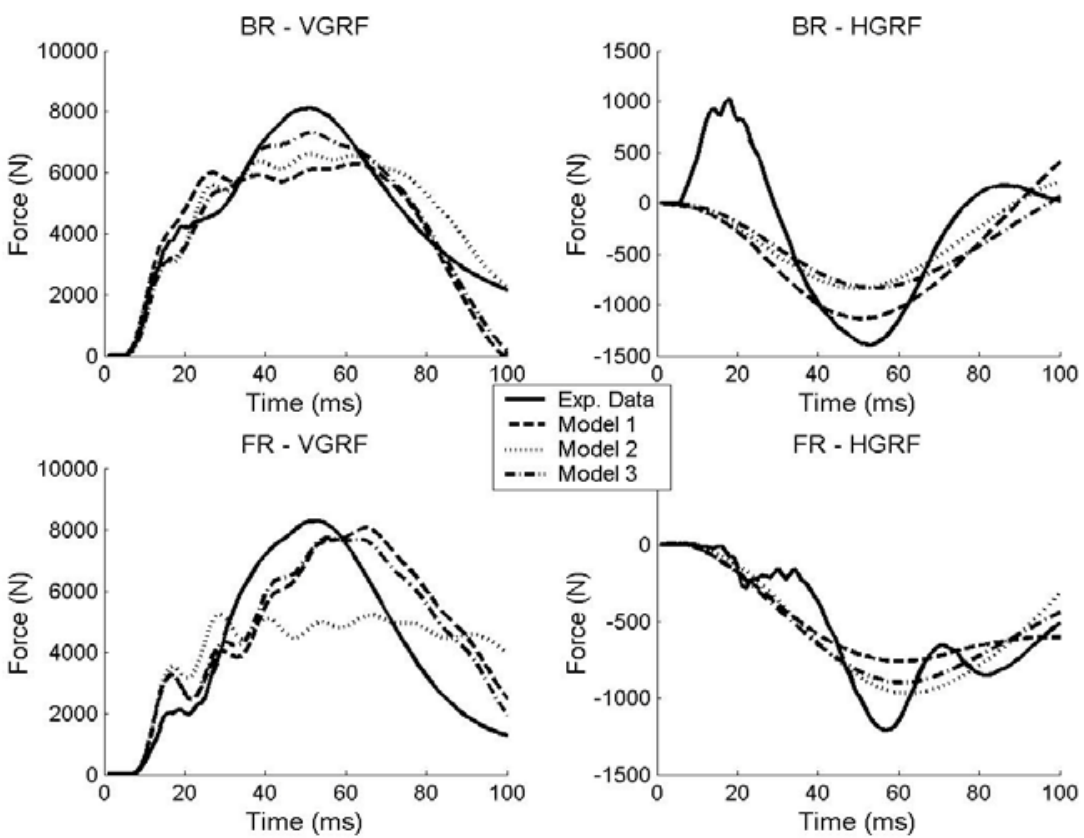

Figure 4. Vertical ground reaction force (VGRF) and horizontal ground reaction force (HGRF) time histories for the experimental data and the three gymnast-mat models. BR is backward rotating and FR is forward rotating. Positive GRF are in the direction of travel. $\mathrm{T}=0$ is time of touchdown. 
The models were able to match the joint angle time histories to $10.7^{\circ}(15 \%)$ or less and all were better at matching the trunk orientation time history during the backward rotating vault than the forward rotating vault (Figure 5).

For evaluation against externally measured values (Table 1) models One, Two and Three were similar (within 8.1\%). However the internal joint reaction forces were, as expected, much higher for the lumped muscle model used in Model Three (Figure 6). Model Three produced joint reaction forces at the ankle up to 2.5 times larger than Model One (Figure 6). The greatest differences were found at the ankle and the smallest were at the hip (Figure 6).

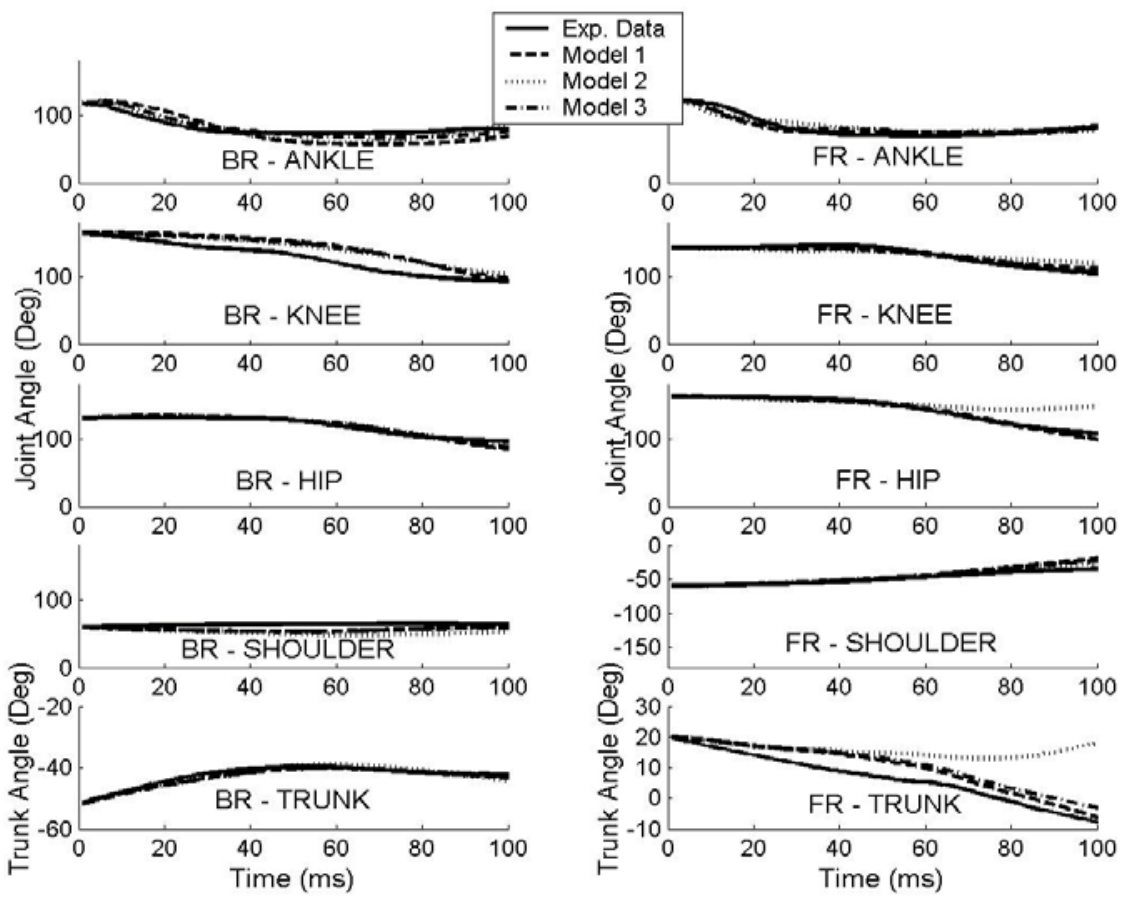

Figure 5. Joint angles and trunk orientation time histories for the experimental data and three gymnast-mat models. BR is backward rotating and FR is forward rotating. $\mathrm{T}=0$ is time of touchdown.
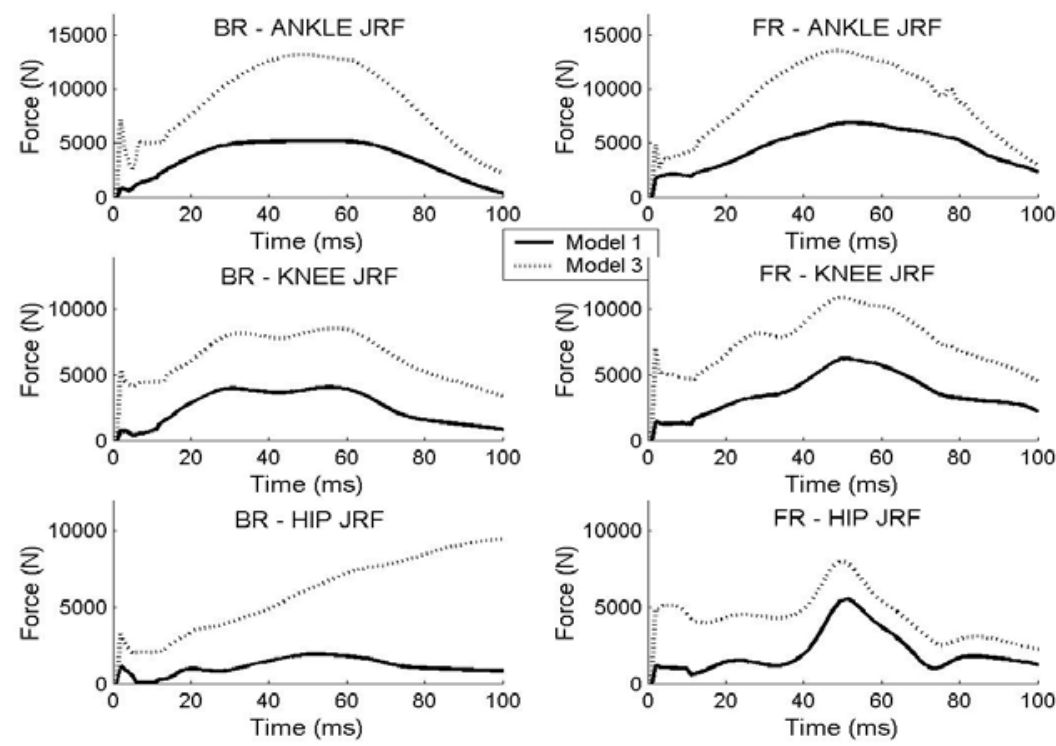

Figure 6. Estimated resultant joint reaction forces using Model One and Model Three. BR is backward rotating and FR is forward rotating. $\mathrm{T}=0$ is time of touchdown. 
Femoral and tibial bone bending moments were estimated to be from $40 \mathrm{Nm}$ to $224 \mathrm{Nm}$ in Model One and from $260 \mathrm{Nm}$ to $363 \mathrm{Nm}$ in Model Three. This was equivalent to a bone bending deformation of $1 \mathrm{~cm}$ to $1.4 \mathrm{~cm}$ in Model Three. The optimised activation time histories for Model Three are similar in shape to the filtered EMG data from the actual trials (Figure 7). For Model One the optimised activations histories were very similar to Model Three at all joints, apart from hip extension where Model One peak extensor torques dropped to $50 \%$ of those in Model Three. Model Two had higher maximum extensor torques at all joints, especially at the knee.

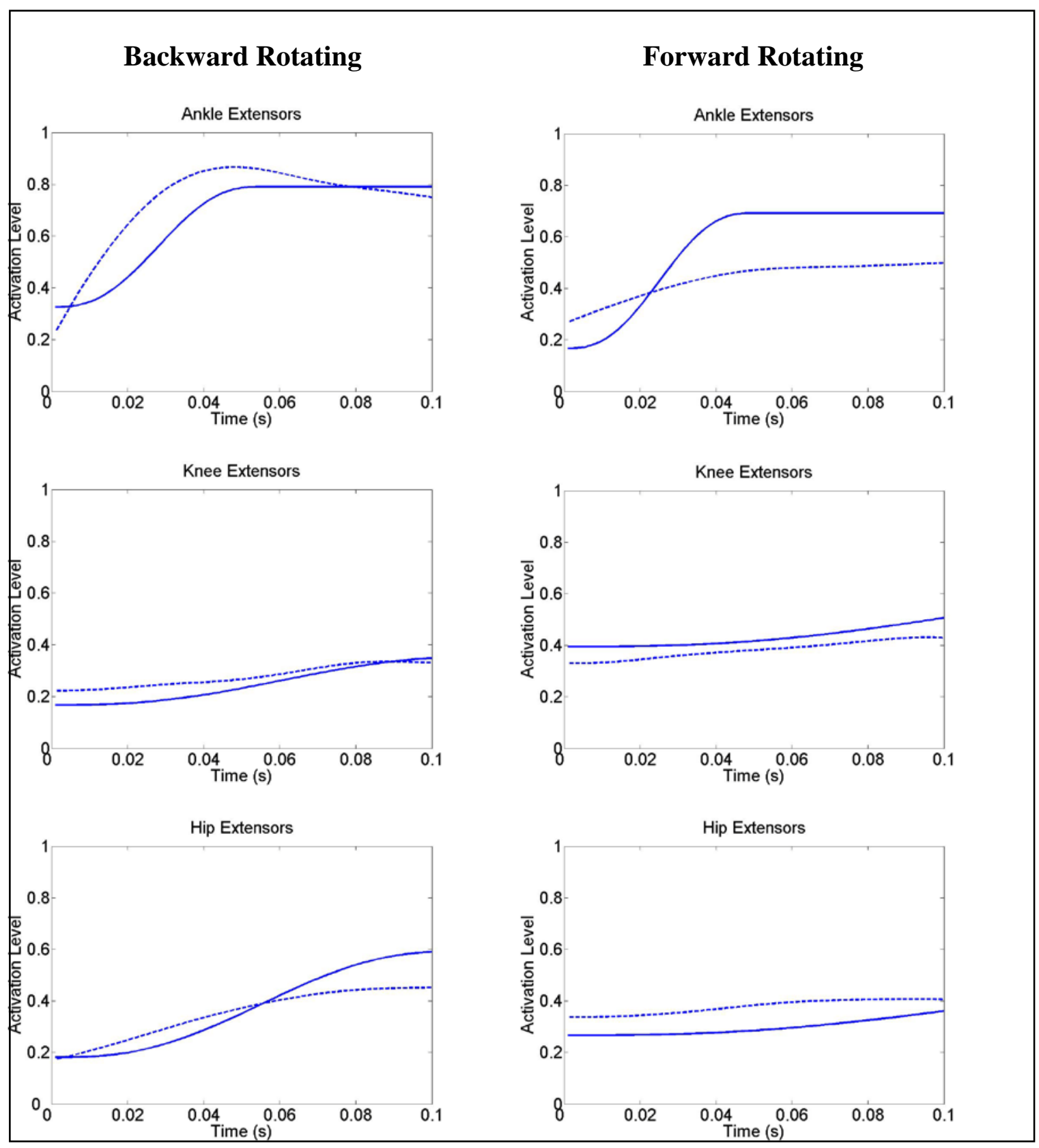

Figure 7. Optimised muscle extensors activation time histories using Model Three and filtered EMG data from actual trials. (Solid line $=$ filtered EMG data, Dashed line $=$ optimised activation history). 


\section{Discussion}

The three models were successful in reproducing the kinetics and kinematics during the first $100 \mathrm{~ms}$ of the vault landings. Model Three performed the best during the simulation of both the forward and backward rotating vaults with overall matching scores of $10.1 \%$ and $16.2 \%$ respectively. Model Two performed markedly worse than the other models and may not have faired well due to problems with integrating the torque generator. The problems were due to the different integration procedures, their accuracy and robustness, used in the different processing environments. At certain times there would be a mismatch leading to an oscillation until they reconverged and this could be solved by working within the same environment for both functions, as in Model Three.

All three models matched the forward rotating vault better than the backward rotating vault, due largely to the poor matching of the HGRF in the backward rotating vault. In the experimental data for the backward rotating vault there was a large initial force in the forward direction of travel of the gymnast (Figure 4) which none of the models were able to reproduce. This peak was unexpected as the kinematic data of the gymnast's feet showed no movement in the direction of travel after the instant of impact. On examination of the high speed video the gymnast could be seen to land with his feet close to the edge of the mat. This caused the customised mat above the force plate to fold under itself, effectively pushing parts of the mat forward whilst the top section remained in the same horizontal location whereas the mat model could not bend and fold. In a full size landing mat this bending would not occur and so it is possible that the poor match of the HGRF for the backward rotating vault is an artefact of the experimental set-up used to avoid cross-bridging.

The matching scores for the joint angle time histories were also noticeably worse for the backward rotating vault. McNitt-Gray (2000) has commented upon vision playing a major role when preparing to land. Perhaps in a backward rotating vault, where a gymnast can 'spot' the landing, a more complex muscle activation pattern is used, whereas in this study each model was restricted to a simplified activation profile. This notion of visual guidance is supported by EMG results from Santello et al. (2001).

Results of the muscle activation profiles revealed fairly high levels of co-contraction prior to landing, which has previously been reported by McNitt-Gray et al. (2001). The muscle activation profiles matched the smoothed EMG measures well in terms of initial activation levels and the time history. Despite the problems associated with normalising EMG signals in very dynamic movements, such as movement artefact from the electronics and soft tissue deformation under the electrodes, the magnitudes were reasonably close. The EMG did indicate that even for these short movement times the activation at the ankle was starting to drop again and a more complex activation pattern in the model may be required in future simulations. In Model Three co-contraction stabilised the joints before impact and allowed rapid changes in the net joint torque to arise once contact with the mat had been made. When co-contracted both sets of muscles were activated, but with only a small or zero net torque. Upon contact with the landing mat the external reaction forces caused the joints to flex producing high velocities. As there were already high activation levels the eccentric muscle forces were immediately large but the concentric forces rapidly fell due to the fact that the muscles were shortening rapidly. This gave a rapid rise in the net extensor torque necessary to control the landing and this effect is likely to have occurred during the landing for the subject.

Model One consistently underestimated joint reaction forces for both forward and backward rotating vaults compared to Model Three. The greatest differences between models One and Three usually occurred at the ankle then the knee and finally the hip, 
although the backward rotating vault had an increasingly larger difference at the hip as the simulation progressed. This is probably due to the GRFs and the joint angles starting to diverge for models One and Three near the end of the simulation, with Model Three performing better. At this point segment accelerations were low so Model One would have low Joint Reaction Forces (JRFs). However, muscle forces were still high and so produced large JRFs in Model Three. The implication is that it is necessary to use linear muscle models in order to determine joint reaction forces as noted by Spagele et al. (1999).

Cyclic loading can cause a material to fail at a load lower than that required to cause failure in an isolated trial due to micro-damage or changes in tissue properties and is often expressed as chronic injury (Pope and Beynnon, 1993). The estimation of internal forces using a muscle-driven model may help to assess both acute and chronic injury risk.

There were no experimental measures of internal joint reaction forces during vault landings with which to compare the values determined in this study. However the model allowed the bending moment at the middle of the shank and thigh to be estimated. As vault landings are known to be strenuous and can lead to pain and injury in trained gymnasts, it would seem likely that the loading would approach the maximum seen in average samples. Martens et al. (1986) found in vitro femoral failure near $400 \mathrm{Nm}$ whereas for Model One maximum bending moments ranged from $40 \mathrm{Nm}$ to $224 \mathrm{Nm}$ and in Model Three ranged from $260 \mathrm{Nm}$ to $363 \mathrm{Nm}$, suggesting that the Model Three values were of the correct magnitude. As mentioned earlier this 2D model cannot account for all the complexities of in vivo 3D loadings from multiple muscles and other passive tissues. Although a lumped muscle model is likely to be inferior to an individual muscle model in terms of complexity, it does have the advantage of subject-specific muscle parameters determination.

The increased complexity of a model required to assess injury risk also increases the time required to run a single simulation. A large proportion of the run time was the mechanical simulation within VN4D and control of the information flow between software packages. The advantages of using a modelling package such as VN4D is that it simplifies model development and in this case would also have allowed the introduction of linear finite element (FE) analysis. Unfortunately the loading to the surfaces of the FE model could not be applied accurately so was not implemented. This highlights some of problems of using modelling packages such as the lack of control of parameters within the package and the inability to format code for optimal run times. Running the whole system within a single language would have decreased the overall run time substantially and would likely have reduced the difference in run times between the models. Overly long run times have implications for the research questions that can be answered for given resources. If simulation time runs into months the number of research questions that could be addressed is reduced and the number of parameters that could be optimized at one time is also limited. This study has shown that a torque-driven model is capable of simulating external kinematics and kinetics during vault landings. If injury risk is to be assessed via the calculation of internal loading then the more complex linear muscle-driven model is required.

\section{References}

Alexander, R., 1990. Optimum take off techniques for high and long jumps. Philosophical Transactions of the Royal Society B329, 3-10.

Allard, P., Stokes, I. A. F., Blanchi, J-P. (1995). Three-Dimensional Analysis of Human Movement. Human Kinetics, Champaign, IL.

Andrish, J. T., 1985. Knee injuries in gymnastics. Clinics in Sports Medicine 4, 111-121.

Chowdhary, A.G., Challis, J.H., 1999. Timing accuracy in human throwing. Journal of Theoretical Biology 201, 219-229. 
Cole, G., Nigg, B., van den Bogert, A., 1996. Lower extremity joint loading during impact in running. Clinical Biomechanics 11, 181-193.

Denoth, J., 1985. The dynamic behaviour of a three-link model of the human body during impact with the ground. In Biomechanics IX-A, International Series on Biomechanics, Champaign, Illinois.

Devita, P., Skelly, W. A., 1992. Effect of landing stiffness on joint kinetics and energetics in the lower extremity. Medicine and Science in Sports and Exercise 24, 108-115.

Duda, G., Brand, D., Freitag, S., Lierse, W., Schneider, E., 1996. Variability of femoral muscle attachments. Journal of Biomechanics 29, 1185-1190.

Dufek, J. T., Bates, B. T., 1990. The evaluation and prediction of impact forces during landings. Medicine and Science in Sports and Exercise 22, 370-377.

Federation Internationale de Gymnastique - F.I.G., 2001. Code of Points - men's artistic gymnastics. F.I.G., Switzerland.

Harringe, M., Renstrom, P., Werner, S., 2006. Injury incidence, mechanism and diagnosis in top-level teamgym: a prospective study conducted over one season. Scandinavian Journal of Medicine and Science in Sports, 1-5.

Hiley, M. J., Yeadon, M. R., 2003. Optimum technique for generating angular momentum in accelerated backward giant circles prior to dismount. Journal of Applied Biomechanics 19, 119-130.

Jacobs, R., Bobbert, M., van Ingen Schenau, G., 1996. Mechanical output from individual muscles during explosive leg extensions: the role of biarticular muscles. Journal of Biomechanics 29, 513-523.

Jensen, J. E., 1998. Stress fracture in a world-class athlete: a case study. Medicine and Science in Sports and Exercise 30, 783-787.

King, M. A., Yeadon, M. R., 2004. Maximising somersault rotation in tumbling. Journal of Biomechanics 37, 471-477.

King, M. A., Wilson, C., Yeadon, M. R., 2006. Evaluation of a torque-driven model of jumping for height. Journal of Applied Biomechanics, 22, 264-274.

Martens, M., van Audekercke, R., de Meester, P., Mulier, J.C., 1986. Mechanical behaviour of femoral bones in bending loading. Journal of Biomechanics 19, 443-54.

McAuley, E., Hudash, G., Shields, K., Albright, J., Garrick, J., Requa, R., Wallace, R., 1987. Injuries in women's gymnastics. The American Journal of Sports Medicine 15, 558566.

McNitt-Gray, J. L., 2000. Musculoskeletal Loading During Landing. In: Zatsiorsky, V. (Eds.), The Encyclopaedia of Sports Medicine: Biomechanics in Sport. IOC, Blackwell Science, pp. 523-549.

McNitt-Gray, J. L., Hester, D. M. E., Mathiyakom, W., Munkasy, B., 2001. Mechanical demand and multijoint control during landing depend on orientation of the body segments relative to the reaction force. Journal of Biomechanics 34, 1471-1482.

McNitt-Gray, J. L., Yokoi, T., Millward, C., 1993. Landing strategy adjustments made by female gymnasts in response to drop height and mat composition. Journal of Applied Biomechanics 9, 173-190.

McNitt-Gray, J. L., Yokoi, T., Millward, C., 1994. Landing strategies used by gymnasts on different surfaces. Journal of Applied Biomechanics 10, 237-252.

Meeusen, R., Borms, J., 1992. Gymnastic injuries. Sports Medicine 13, 337-356.

Mills, C., Pain, M. T. G., Yeadon, M. R., 2006. Modelling a viscoelastic gymnastics landing mat during impact. Journal of Applied Biomechanics 22, 103-111.

Ozguven, H. N., Berme, N., 1988. An experimental and analytical study of impact forces during human jumping. Journal of Biomechanics 21, 1061-1066. 
Pain, M.T.G., Challis, J. H., 2006. The influence of soft tissue movement on ground reaction forces, joint torques and joint reaction forces in drop landings. Journal of Biomechanics 39, 119-124.

Pain, M. T. G., Mills, C., Yeadon, M.R., 2005. Video analysis of the deformation and effective mass of gymnastics landing mats. Medicine and Science in Sports and Exercise 37, 1754-1760.

Pettrone, F., Ricciardelli, E., 1987. Gymnastic injuries: the Virginia experience 1982-1983. The American Journal of Sports Medicine 15, 59-62.

Pope, M., Beynnon, B., 1993. Sports Injuries: Basic Principles of Prevention \& Care. In: P.A.F.H. Renstrom (Eds.), The Encyclopaedia of Sports Medicine, Blackwell Scientific Publications, London, UK, pp. 120-134.

Santello, M., McDonagh, M. J.N., Challis, J.H., 2001. Visual and non-visual control of landing movements in humans. Journal of Physiology 537, 313-327.

Snook, G. A., 1979. Injuries in women's gymnastics. The American Journal of Sports Medicine 7, 242-244.

Spagale, T., Kistner, A., Gollhofer, A., 1999. Modelling, simulation and optimisation of a human vertical jump. Journal of Biomechanics 32, 521-530.

Woltring, H.J., 1986. A Fortran package for generalised cross-validatory spline smoothing and differentiation. Advanced Engineering Software 8, 104-113.

Yeadon, M. R., 1990. The simulation of aerial movement - II. A mathematical inertia model of the human body. Journal of Biomechanics 23, 67-74.

Yeadon, M. R., King, M. A., Wilson, C., 2006. Modelling the maximum voluntary joint/angular velocity relationship in human movement. Journal of Biomechanics 39, 476-482.

\section{Appendix}

Table A1. Subject Anthropometric Data (left side only reported)

\begin{tabular}{|c|c|c|c|c|c|c|}
\hline Segment & $\begin{array}{l}\text { Mass } \\
\text { (kg) }\end{array}$ & $\begin{array}{l}\text { Dist CM to } \\
\text { prox joint } \\
\text { (m) }\end{array}$ & $\begin{array}{l}\text { Segment } \\
\text { Length (m) }\end{array}$ & $\begin{array}{l}\text { Moment of } \\
\text { Inertia } \\
\text { (Somersault) } \\
\left(\mathrm{kgm}^{2}\right)\end{array}$ & $\begin{array}{l}\text { Moment of } \\
\text { Inertia } \\
\text { (Tilt) } \\
\left(\mathrm{kgm}^{2}\right) \\
\end{array}$ & $\begin{array}{l}\text { Moment } \\
\text { of Inertia } \\
\text { (Twist) } \\
\left(\text { (kgm }^{2}\right)\end{array}$ \\
\hline Trunk + Head & 37.422 & 0.361 & 0.871 & 2.058 & 2.046 & 0.324 \\
\hline Upper Arm & 2.599 & 0.105 & 0.270 & 0.015 & 0.015 & 0.004 \\
\hline Lower arm & 2.000 & 0.186 & 0.464 & 0.029 & 0.029 & 0.001 \\
\hline Thigh & 9.520 & 0.170 & 0.398 & 0.135 & 0.135 & 0.034 \\
\hline Shank & 4.723 & 0.196 & 0.442 & 0.074 & 0.074 & 0.007 \\
\hline Upper foot & 1.128 & 0.071 & 0.154 & 0.003 & 0.003 & 0.001 \\
\hline Lower foot & 0.123 & 0.024 & 0.061 & 0.00009 & 0.00009 & 0.00006 \\
\hline
\end{tabular}

Table A2. Wobbling mass distribution

\begin{tabular}{|l|l|l|l|l|}
\hline Segment & Total Mass (kg) & Wobble (kg) & Bone (kg) & Bone (\%) \\
\hline Trunk + Head & 37.42 & 30.41 & 7.01 & 18.7 \\
\hline Upper Arm & 5.52 & - & - & - \\
\hline Lower Arm + Hand & 4.10 & - & - & - \\
\hline Upper Leg (Thigh) & 19.07 & 16.08 & 2.99 & 15.7 \\
\hline Lower Leg (Shank) & 9.54 & 6.63 & 2.91 & 30.5 \\
\hline Upper Foot & 2.27 & - & - & - \\
\hline Lower Foot & 0.28 & - & - & - \\
\hline
\end{tabular}


Table A3. Strength Parameters (9 parameter function)

\begin{tabular}{|l|l|l|l|l|l|l|l|l|}
\hline Parameter & $\begin{array}{l}\text { Ankle } \\
\text { Plantar } \\
\text { Flexion }\end{array}$ & $\begin{array}{l}\text { Ankle } \\
\text { Dorsi } \\
\text { Flexion }\end{array}$ & $\begin{array}{l}\text { Knee } \\
\text { Extension }\end{array}$ & $\begin{array}{l}\text { Knee } \\
\text { Flexion }\end{array}$ & $\begin{array}{l}\text { Hip } \\
\text { Extension }\end{array}$ & $\begin{array}{l}\text { Hip } \\
\text { Flexion }\end{array}$ & $\begin{array}{l}\text { Shoulder } \\
\text { Extension }\end{array}$ & $\begin{array}{l}\text { Shoulder } \\
\text { Flexion }\end{array}$ \\
\hline $\mathrm{T}_{0}(\mathrm{Nm})$ & 255 & 36 & 242.2 & 146.3 & 239.9 & 131.9 & 116.2 & 85.3 \\
\hline$\omega_{\max }\left({ }^{\circ} / \mathrm{s}\right)$ & 1600 & 1600 & 2000.0 & 2000.0 & 1600.0 & 1600.0 & 2000.0 & 2000.0 \\
\hline$\omega_{\mathrm{c}}(\% / \mathrm{s})$ & 588.7 & 316.3 & 664.8 & 381.6 & 523.4 & 203.0 & 577.9 & 364.4 \\
\hline $\mathrm{a}_{\min }$ & 0.8 & 0.8 & 0.9 & 0.8 & 0.8 & 0.8 & 0.8 & 0.9 \\
\hline $\mathrm{m}$ & 16.6 & 5.3 & 15.5 & 3.6 & 15.8 & 5.1 & 18.4 & 7.3 \\
\hline$\omega_{1}(\% / \mathrm{s})$ & -82.6 & -52.4 & -130.9 & -25.9 & -44.4 & -17.3 & -72.4 & -114.0 \\
\hline $\mathrm{T}_{\max }(\mathrm{Nm})$ & 382 & 54 & 363.3 & 219.5 & 359.9 & 197.9 & 174.3 & 128.0 \\
\hline $\mathrm{r}$ & 0.00009 & 0.000095 & 0.00036 & 0.00015 & 0.000061 & 0.0000043 & 0.000027 & 0.000026 \\
\hline$\theta_{\text {opt }}\left({ }^{\circ}\right)$ & 116 & 104 & 127 & 148 & 56 & 359 & 153 & 155 \\
\hline
\end{tabular}

$\mathrm{T}_{0}=$ maximum isometric torque

$\mathrm{T}_{\max }=$ maximum torque

$\omega_{\max }=$ maximum angular velocity when torque equals zero

$\omega_{c}=$ asymptote of angular velocity in concentric/eccentric hyperbola

$\mathrm{a}_{\min }=$ minimum activation level in eccentric phase

$\mathrm{m}=$ the inverse of the slope of activation angular velocity function

$\omega_{1}=$ angular velocity at mid-point of the slope

$r=$ rate at which torque drops off from optimal angle

$\theta_{\mathrm{opt}}=$ optimum angle at which maximum torque occurs

Table A4. Spring-damper Parameters for Wobbling Masses

\begin{tabular}{|l|l|l|}
\hline Model Parameter & Stiffness $\left(\mathbf{1 0}^{\mathbf{8}} \mathbf{N}\right)$ & Damping (Ns/m) \\
\hline Trunk + Head (Torso) & 2.3 & 700 \\
\hline Upper Leg (Thigh) & 1.8 & 560 \\
\hline Lower Leg (Shank) & 0.9 & 280 \\
\hline
\end{tabular}

Table A5. Subject SEC Stiffness and Moment Arm

\begin{tabular}{|l|l|l|l|}
\hline Joint movement & SEC stiffness $\left(\mathbf{N m} /{ }^{\circ}\right)$ & SEC stiffness $\left.\mathbf{( N m}^{-\mathbf{1}}\right)$ & Moment arm Range (mm) \\
\hline Ankle plantar flexion & 7.5 & 3511942 & $26-59$ \\
\hline Ankle dorsi flexion & 1.7 & 76695 & $34-50$ \\
\hline Knee extension & 11.2 & 382154 & $33-46$ \\
\hline Knee flexion & 4.3 & 530909 & $15-43$ \\
\hline Hip extension & 61.5 & 1017000 & $40-59$ \\
\hline Hip flexion & 7.3 & 776699 & $11-30$ \\
\hline Shoulder flexion & 26.2 & - & - \\
\hline Shoulder extension & 26.2 & - & - \\
\hline
\end{tabular}

SEC stiffnesses derived from Allard, et al. (1995); Moment arms derived from Duda et al. (1996); Jacobs et al. (1996). The table values were used to determine the force in the linear series elastic component equation $\mathrm{F}=-\mathrm{kx}$. In conjunction with the moment arm data an equivalent angular equation was used to calculate the torque.

Table A6. Landing mat parameters

\begin{tabular}{|l|l|l|l|l|l|}
\hline & $\begin{array}{l}\text { Mass of Layer } \\
\mathbf{( k g )}\end{array}$ & $\begin{array}{l}\text { Vertical } \\
\text { Stiffness (N/m) }\end{array}$ & $\begin{array}{l}\text { Vertical } \\
\text { Damping } \\
(\mathbf{N s} / \mathbf{m})\end{array}$ & $\begin{array}{l}\text { Horizontal } \\
\text { Stiffness } \\
\mathbf{( N / m )}\end{array}$ & $\begin{array}{l}\text { Horizontal } \\
\text { Damping } \\
(\mathbf{N s} / \mathbf{m})\end{array}$ \\
\hline Layer 1 & gymnast & 61080 & 350 & \multirow{2}{*}{15417} & \multirow{2}{*}{557} \\
\cline { 1 - 5 } Layer 2 & 2.44 & 57530 & 430 & & \\
\hline Layer 3 & 3.67 & 928210 & 290 & & \\
\hline
\end{tabular}

Table A7. Initial Conditions 


\begin{tabular}{|l|l|l|}
\hline Parameter & Backward Rotating Vault & Forward Rotating Vault \\
\hline Vertical Velocity at Impact $(\mathrm{m} / \mathrm{s})$ & 6.4 & 5.2 \\
\hline Horizontal Velocity of Impact $(\mathrm{m} / \mathrm{s})$ & 1.1 & 0.4 \\
\hline Shoulder Angle $\left(^{\circ}\right)$ & 60 & -60 \\
\hline Hip Angle $\left(^{\circ}\right)$ & 130 & 162 \\
\hline Knee Angle $\left(^{\circ}\right)$ & 165 & 143 \\
\hline Ankle Angle $\left(^{\circ}\right)$ & 118 & 122 \\
\hline MP Angle $\left(^{\circ}\right)$ & 156 & 164 \\
\hline Elbow Angle $\left(^{\circ}\right)$ & 180 & 165 \\
\hline Trunk Angle $\left({ }^{\circ}\right)$ & -51.5 & 19.6 \\
\hline Shoulder Angular Velocity $\left({ }^{\circ} / \mathrm{s}\right)$ & 150 & -100 \\
\hline Hip Angular Velocity $\left({ }^{\circ} / \mathrm{s}\right)$ & 75 & -100 \\
\hline Knee Angular Velocity $\left({ }^{\circ} / \mathrm{s}\right)$ & -50 & 25 \\
\hline Ankle Angular Velocity $\left({ }^{\circ} / \mathrm{s}\right)$ & -50 & 25 \\
\hline
\end{tabular}

NB. Positive angular velocity indicated that the joint was extending and a negative indicated that the joint was flexing. Trunk angle is the angle to the vertical. 
Table A8. Initial activation levels and timings determined from EMG. Values are between 0 and 1 and represent the activation for one leg. An activation of 1 means the leg is activated maximally. Timings refer to when the activation will ramp from minimum to maximum for the quintic function.

\begin{tabular}{|l|l|l|l|l|}
\hline \multirow{2}{*}{ Parameter } & \multicolumn{4}{|l|}{ Skill } \\
\cline { 2 - 5 } & $\begin{array}{l}\text { Back Rotating } \\
\text { (Activation Level) }\end{array}$ & $\begin{array}{l}\text { Back Rotating } \\
\text { (Timings / s) }\end{array}$ & $\begin{array}{l}\text { Forward Rotating } \\
\text { (Activation Level) }\end{array}$ & $\begin{array}{l}\text { Forward Rotating } \\
\text { (Timings / s) }\end{array}$ \\
\hline Ankle Flexors & 0.50 & 0.10 & 0.25 & 0.10 \\
\hline Ankle Extensors & 0.35 & 0.06 & 0.25 & 0.05 \\
\hline Knee Flexors & 0.65 & 0.13 & 0.25 & 0.20 \\
\hline Knee Extensors & 0.25 & 0.10 & 0.50 & 0.23 \\
\hline Hip Flexors* & 0.25 & 0.11 & 0.35 & 0.20 \\
\hline Hip Extensors* & 0.35 & 0.20 & 0.35 & 0.23 \\
\hline Shoulder Flexors ** & 0.25 & 0.50 & 0.25 & 0.30 \\
\hline Shoulder Extensors ** & 0.50 & 0.20 & 0.1 & 0.20 \\
\hline
\end{tabular}

* The rectus femoris muscle was used to estimate hip flexor activation levels. Although this was likely to overestimate the hip flexor values, as it was acting as a knee extensor during landing.

** There was no EMG of the shoulders. These values are estimates based on activation levels that reproduced the pre-landing shoulder motion. 